ISSN: 0210-1696

DOI: https://doi.org/10.14201/scero20215232936

\title{
DEFINING, DIAGNOSING, CLASSIFYING, AND PLANNING SUPPORTS FOR PEOPLE WITH INTELLECTUAL DISABILITY: AN EMERGING CONSENSUS
}

\section{Definición, diagnóstico, clasificación y planificación de apoyos para personas con discapacidad intelectual: un consenso emergente}

Robert L. SCHALOCK

Hastings College (Nebraska)

rchalock@ultraplix.com

Ruth LUCKASSON

University of New Mexico. Department of Special Education

Marc J. TAssé

Nisonger Center-UCEDD

The Ohio State University. Departments of Psychology and Psychology

Recepción: 12 de enero de 2021

Aceptación: 11 de febrero de 2021

AвSTRACT: Significant international work in the field of intellectual disability (ID) over the last decade has resulted in an emerging consensus regarding the definition of ID, the criteria used to diagnose a person with ID, the classification of individuals who have been diagnosed with ID, and the planning of individualized supports for people with ID. This article describes that emerging consensus.

KEYWORDs: intellectual disability; definition; diagnosis; classification; planning supports. 
Resumen: Durante la última década, un importante trabajo internacional en el ámbito de la discapacidad intelectual (DI) ha dado lugar a un consenso emergente con respecto a la definición de DI, los criterios utilizados para diagnosticar a una persona con DI, la clasificación de las personas que han sido diagnosticadas con DI y la planificación de apoyos individualizados para personas con DI. Este artículo describe ese consenso emergente.

Palabras Clave: discapacidad intelectual; definición; diagnóstico; clasificación; planificación de apoyos.

\section{Introduction and overview}

IgNificANT INTERNATIONAL WORK in the field of intellectual disability (ID) over the last decade has resulted in an emerging consensus regarding the definition of ID, the criteria used to diagnose a person with ID, the classification of individuals who have been diagnosed with ID, and the planning of individualized supports for people with ID. This work, which is enumerated in the published literature referenced herein, has been incorporated into current and anticipated manuals published by AAIDD (Schalock et al., 2021), DSM-5 (APA, 2013), and ICD-11 (WHO, 2018). The purpose of this article is to describe the emerging consensus regarding the definition of ID, the diagnosis of ID, the classification of individuals with ID, and the planning of supports for people with ID.

\section{The definition of intellectual disability}

The purpose of a definition of ID is to establish the meaning and boundaries of the term, and separate who is included within the term from those who are outside the term. The consensus, across AAIDD, DSM-5, and ICD-11, is that ID is characterized by significant limitations both in intellectual functioning and adaptive behavior, and originates during the developmental period. This consensus is evident in the following definitions of ID. Although these three diagnostic systems agree that the level of intellect functioning and adaptive behavior and age of onset during the developmental period lead to making a determination of ID, the terminology used differs slightly.

- Intellectual disability is characterized by significant limitations both in intellectual functioning and adaptive behavior as expressed in conceptual, social, and practical adaptive skills. This disability originates during the developmental period, which is defined operationally as before the individual attains age 22 (Schalock et al., 2021).

- Intellectual disability (intellectual developmental disorder) is a disorder with onset during the developmental period that includes both intellectual and adaptive behavior deficits in conceptual, social, and practical domains (DSM-5, APA, 2013).

- Disorders of intellectual development are a group of etiologically diverse conditions originating during the developmental period characterized by signifi- 
DEFINING, DIAGNOSING, CLASSIFYING, AND PLANNING SUPPORTS FOR PEOPE

WITH INTELLECTUAL DISABILITY: AN EMERGING CONSENSUS

R. L SCHALOCK, R. LUCKASSON Y M. J. TASSÉ

cantly below average intellectual functioning and adaptive behavior (ICD-11, WHO, 2018).

\section{Assumptions regarding implementing a definition of ID}

Assumptions are an essential part of a definition of ID because they clarify the context from which the definition arises and indicate how the definition should be applied. Thus, a definition of ID cannot stand alone. As presented in Schalock et al. (2021), the following assumptions are essential to implementating a definition of ID.

1. Limitations in present functioning must be considered within the context of community environments typical of the individual's age peers and culture.

2. Valid assessment considers cultural and linguistic factors, as well as differences in communication, sensory, motor, and behavioral factors.

3. Within an individual, limitations often coexist with strengths.

4. An important purpose of describing limitations is to develop a profile of needed supports.

5. With appropriate personalized supports over a sustained period, the life functioning of the person with ID generally will improve.

\section{The Diagnosis of intellectual disability}

Making a diagnosis of ID requires verifying that there are significant limitations in both intellectual functioning and adaptive behavior, and that the disability originates during the developmental period. In reference to each of these three criteria, there is an emerging consensus that:

- The criterion for significant limitations in intellectual functioning is a fullscale IQ score that is approximately two standard deviations or more below the population mean, considering the standard error of measurement (SEM) of the specific, individually administered instrument used. The SEM, which varies by test, subgroup, and age group, should be used to establish a statistical confidence interval within which the person's true score falls. Best practices recommend interpreting all obtained standard scores using the $95 \%$ confidence interval (i.e., the obtained score plus or minus 2 times the SEM).

- The criterion for significant limitations in adaptive behavior is an adaptive behavior score that is approximately two standard deviations or more below the population mean in at least one of the three adaptive behavior domains: conceptual, social, and practical, considering the SEM of the specific, individually administered instrument used. As with intellectual functioning, the SEM is used to establish the $95 \%$ confidence interval within which the person's true score falls (i.e., the obtained score plus or minus 2 times the SEM). It is important to note that because intellectual disability occurs worldwide a common nomenclature and descriptors are necessary for global health statistics and re- 
porting. In some low-income countries standardized assessment of intellectual functioning and/or adaptive behavior may not be feasible, behavioral indicators to guide clinical judgment in determining the individual's level of functioning across all three domains of adaptive behavior (conceptual, social, and practical) have been developed by Tassé et al. (2019). We expect these behavioral indicators will be incorporated into the ICD-11.

- The age of onset criterion is essential in a diagnosis of ID because it establishes when ID as a developmental disability originates. The operational definition of age of onset may vary across cultures and ethnic groups based on social roles and family interactions, educational involvement, and career development. Best practices emphasize that the age of onset is established and documented at the time of the evaluation, and includes a thorough review of the individual's social, medical, and educational history.

In reference to the emerging consensus summarized above regarding the significant limitations in intellectual functioning and adaptive behavior criteria for a diagnosis of ID, equal weight and joint consideration should be given to intellectual functioning and adaptive behavior in the diagnosis of ID. Specifically, an extensive review of the literature indicates that intellectual functioning and adaptive behavior are separate constructs and only moderately correlated (Alexander and Reynolds, 2020; Tassé et al., 2016).

\section{The classification of individuals with intellectual disability}

There is an emerging consensus in the field of ID that classification: (a) is not a diagnosis; (b) is an optional post-diagnosis organizing scheme used to categorize information to better understand a person's needs; and (c) should have benefit to the individual (Schalock and Luckasson, 2015; Schalock et al., 2021). What is still emerging in the field is agreement on what should be classified.

Historically, people with ID were classified according to either an estimate of their level of intellectual functioning or on the basis of an IQ score. The use of IQ to classify people was due in large part to the availability of IQ tests, the belief that low intellectual functioning was the major characteristic of ID, and an erroneous assumption of IQ's predictive value regarding personal outcomes. This overreliance on IQ for classification has been replaced by a multi-dimensional approach to subgroup classification that involves classifying individuals with a diagnosis of ID into subgroups based on the intensity of their support needs, the extent of their adaptive behavior limitations in conceptual, social, and practical skills, and/or the extent of their limitation in intellectual functioning (Schalock et al., 2021). The emergence of this multidimensional approach to subgroup classification has been due to:

- The incorporation of the supports paradigm into the ID field and the development of standardized support need assessment instruments (Arnold et al., 2014; Thompson et al., 2015, 2016). 
DEFINING, DIAGNOSING, CLASSIFYING, AND PLANNING SUPPORTS FOR PEOPE

WITH INTELLECTUAL DISABILITY: AN EMERGING CONSENSUS

R. L SCHALOCK, R. LUCKASSON Y M. J. TASSÉ

- The development of standardized adaptive behavior assessment instruments that provide standard scores in conceptual, social, and practical skills (Harrison and Oakland, 2015; Pearson et al., 2015; Sparrow et al., 2016; Tassé et al., 2017).

- The development of an explicit framerwork and systematic subgroup classification process. The process involves: (a) stating the important purpose for the subgroup classification (e.g., to better understand a person's needs in reference to the intensity of support needs, the extent of limitations in conceptual, social, and practical adaptive skills, and/or the extent of limitations in intellectual functioning); (b) using relevant data sets to address the classification's purpose (i.e., intensity of support needs index, adaptive behavior standard scores, and/ or a standardized full-scale IQ score); (c) describing the data-driven procedures used to establish the subgroup classification categories (e.g. standardized support need assessment instruments, standardized adaptive behavior scales, or standardized IQ tests); and (d) using empirically based subgroup classification bands to establish the subgroup classification categories (Schalock and Luckasson, 2015; Schalock et al., 2021).

This multidimensional approach to subgroup classification is currently used in published classification systems to establish subgroups on the basis of the intensity of an individual's support needs or the extent of their adaptive behavior limitations. For example, AAIDD proposes that subgroup classification should be based on the intensity of support needs (Schalock et al., 2021). Similarly, DSM-5 has abandoned the use of IQ scores in subgrouping, and proposes instead that the individual's level of adaptive behavior and the level of support needs should be used (APA, 2013). In contrast, ICD-11 proposes that subgroup classification should be based on considering both the individual's level of intellectual functioning and level of adaptive behavior (WHO, 2018).

\section{The planning of supports for people with intellectual disability}

The planning of supports for people with ID is framed by the social-ecological model of disability and the supports paradigm. The former focuses on "the fit" between people and their environments, and conceptualizes disability as the expression of limitations in individual functioning within a social context. The supports paradigm is based on the premise that: (a) the most relevant difference between people with ID and the general population is that people with ID need different types and intensities of supports to fully participate in and contribute to society; and (b) supports lessen (i.e., compensate, mitigate, or ameliorate) the impact of the disability, but do not eliminate the disability itself (Thompson et al., 2014). Within this context, there is an emerging consensus that the planning of supports for people with ID should be person-centered, comprehensive, coordinated, and outcome oriented. 
- Person-centeredness involves planning supports based on the pattern and intensity of assessed support needs across major life activity areas, the pattern and intensity of exceptional medical and behavioral support needs, and the personal goals of the individual (Stancliffe et al., 2016; Thompson et al., 2015, 2016). Person-centeredness also focuses on: (a) support facilitating conditions that involve equity, flexibility, the availability and accessibility of supports, safe environments, information about the elements of systems of supports, and consistency in supports provision (Verdugo et al., in press); and (b) support relationships that include respect, responsiveness, reliability, communication, commitment, understanding, and empathy (Buntinx et al., 2018; Qian et al., 2019).

- Comprehensiveness involves employing systems of supports whose elements include: (a) choice and personal autonomy (i.e., opportunities to make choices and exercise self-determination); (b) inclusive environments (i.e., natural environments in which people with and without disabilities are included and valued); (c) generic supports (i.e., supports that are available to everyone); and (d) specialized supports (i.e., professionally-based interventions, therapies, and strategies) (Schalock et al., 2021).

- Coordination is facilitated through the development, implementation, and evaluation of a Personal Support Plan (PSP) that provides a systematic, integrated approach to the planning and provision of supports. Support coordination factors involve aligning personal goals and support needs to specific support strategies, implementing and reviewing the plan, monitoring implementation fidelity, incorporating change, and emphasizing a user-friendly format that is developed by a horizontally structured education or support team that meaningfully includes the person with a disability (Schalock et al., 2018; Thompson et al., 2015).

- Outcome-oriented involves using an outcome oriented framework to plan, provide, and evaluate supports. Such a framework, which is built around human functioning dimensions or quality of life/personal well-being domains, is used to align support needs, support strategies, and valued outcome indicators (Gómez and Verdugo, 2016; Luckasson and Schalock, 2013; Schalock et al., 2018).

\section{Conclusion}

The emerging consensus described in this article regarding defining, diagnosing, classifying, and planning supports for people with ID has emerged in a field that is undergoing a significant transformation. This transformation is characterized by a holistic and functional approach to ID, the social-ecological model of disability and a supports-based service delivery system, the increasing use of data-based decision making and evidence-based practices, respect for the empowerment of individuals and their families, and an increased emphasis on professional responsibility (Schalock et al., in press; Schalock and Verdugo, 2019). 
The transformation that is occurring in the field of ID is both the cause and effect of the emerging consensus. This cause-effect interactive relationship reflects the dynamic nature of change, and suggests that the emerging consensus may change as the field continues to increase its understanding of ID, and is buffeted by current and future social, political, and financial challenges. During these times of change, individuals and their families, policy makers, funders, clinicians, support providers, and researchers should advocate for the principles, values, and practices that underlie the consensus described in this article. Specifically, advocacy is needed to ensure that:

- The definition of ID continues to be aligned among national and international disability organizations, and be based on the criteria of significant limitations in intellectual functioning and adaptive behavior as expressed in conceptual, social, and practical skills, and the age of onset during the developmental period.

- The diagnosis of ID continues to be based on best practices related to both the assessment of intellectual functioning and adaptive behavior, and the interpretation of IQ and adaptive behavior scores.

- The subgroup classification of people with a diagnosis of ID is a post-diagnosis schema that is based on a clear person-centered purpose, an empirically-based framework and systematic process, and benefits the person.

- Individualized supports are provided to promote the development and interests of people and enhance their functioning and personal well-being, and that the resources and strategies used in supports provision are person-centered, comprehensive, coordinated, and outcome oriented.

\section{Bibliographic references}

Alexander, R. M. and Reynolds, M. R. (2020). Intelligence and adaptive behavior: a meta-analysis. School Psychology Review, 49, 85-110. https://doi.org/10.1080/237296 6x.2020.1717374

American Psychiatric Association. (2013). Diagnostic and statistical manual for mental disorders ( $5^{\text {th }}$ ed.). American Psychiatric Publishing.

Arnold, S. R. C., Riches, V. C. and Stancliffe, R. (2014). I-Can: the classification and prediction of support needs. Journal of Applied Research in Intellectual Disabilities, 27, 97-111.

Buntinx, W. H. E., Yu Tan, I. and Aldenkamp, A. P. (2018). Support values through the eyes of the patient: an explanatory study into long-term support of persons with refractory epilepsy. Epilepsy and Behavior, 82, 155-163.

Gómez, L. E. and Verdugo, M. Á. (2016). Outcome evaluation. In R. L. Schalock and K. D. KeITH (Eds.), Cross-cultural quality of life: enhancing the lives of people with intellectual disability (pp. 71-80). American Association on Intellectual and Developmental Disabilities.

Harrison, P. L. and Oakland, T. (2015). Adaptive Behavior Assessment System: Third Edition (Abas-3). Pearson Publishing.

Luckasson, R. and SCHALOCK, R. L. (2013). Defining and applying a functionality approach to intellectual disability. Journal of Intellectual Disability Research, 57, 657-668. 
Pearson, N. A., Patton, J. R. and Mruzek, D. W. (2015). Adaptive Behavior Diagnostic Scale (ABDS). Pro-ed.

Qian, X., Larson, S., Ticha, R., Stancliffe, R. and Pettingell, S. L. (2019). Active support training, staff assistance, and engagement of individuals with intellectual and developmental disabilities in the United States: randomized controlled trial. American Journal on Intellectual and Developmental Disabilities, 124, 157-173.

SCHALOCK, R. L. and LUCKASSON, R. (2015). A systematic approach to subgroup classification in intellectual disability. Intellectual and Developmental Disabilities, 53, 358-366.

Schalock, R. L., Luckasson, R. and TAssé, M. J. (in press). Ongoing transformation in the field of IDD: taking action for future progress. Intellectual and Developmental Disabilities.

Schalock, R. L., Luckasson, R. and TAssé, M. J. (2021). Intellectual disability: definition, diagnosis, classification, and systems of supports (12 ${ }^{\text {th }} \mathrm{ed}$.). AAIDD.

Schalock, R. L., Thompson, J. R. and TAssé, M. J. (2018). A systematic approach to personal support plans. AAIDD.

Schalock, R. L. and Verdugo, M. Á. (2019). International developments influencing the field of intellectual and developmental disabilities. In K. D. KeITH (Ed.), Cross-cultural psychology: contemporary themes and perspectives (pp. 309-323). Wiley-Blackwell.

Sparrow, S. S., Cicchetti, D. V. and Saulnier, C. A. (2016). Vineland Adaptive Scales (3 ${ }^{\text {rd }}$ ed.) Pearson.

Stancliffe, R. J., Arnold, S. R. C. and Riches, V. C. (2016). The supports paradigm. In R. L. Schalock and K. D. KeITh (Eds.), Cross-cultural quality of life: enhancing the lives of people with intellectual disability (pp. 133-142). American Association on Intellectual and Developmental Disabilities.

Tassé, M. J., Balboni, G., Navas P., Luckasson, R., Nygren, M. A., Belacchi, C., Reed, G. M. y Kogan, C. S. (2019). Developing behavioral indicators for intellectual functioning and adaptive behavior for ICD-11 disorders of intellectual development. Journal of Intellectual Disability Research, 63, 386-407.

Tassé, M. J., Luckasson, R. and Schalock, R. L. (2016). The relation between intellectual functioning and adaptive behavior in the diagnosis of intellectual disability. Intellectual and Developmental Disabilities, 54, 381-390.

Tassé, M. J., Schalock, R. L., Balboni, G., Bersani, H., Borthwick-Duffy, S. A., Spreat, S., Thissen, K. F. W. and Zhang, K. (2017). Diagnostic Adaptive Behavior Scale user's manual. AAIDD.

Thompson, J. R., Bryant, B. R., Schalock, R. L., Shogren, K. A., Tassé, M. J., Wehmeyer, M., Campbell, E. M., Crais, E. M., Hughes, C. and Rotholz, D. A. (2015). Supports Intensity Scale-Adult version user's guide. AAIDD.

Thompson, J. R., Schalock, R. L., Agosta, J., Teninty, L. and Fortune, J. (2014). How the supports paradigm is transforming service systems for persons with intellectual and related developmental disabilities. Inclusion, 2, 86-99.

Thompson, J. R., Wehmeyer, M. L., Hughes, C., Shogren, K. A., Seo, H., Little, T. D., Seo, H., Schalock, R. L. and TAssé, M. J. (2016). Supports Intensity Scale-Children's Version (SIS-C). Interview and profile form. AAIDD.

Verdugo, M. Á., Schalock, R. L. and Gómez, L. E. (in press). El Modelo de Calidad de Vida y Apoyos: La unión tras veinticinco años de caminos paralelos. Siglo Cero.

World Health Organization. (2018). ICD-11 beta draft. https://icd.who.int/dev11/1-m/en 